\title{
Ativismo alimentar e consumo político - Duas gerações de ativismo alimentar no Brasil ${ }^{1}$
}

\author{
Fátima Portilho \\ Universidade Federal Rural do Rio de Janeiro - Rio de Janeiro - RJ - \\ Brasil \\ ORCID: 0000-0003-4780-9547
}

\section{Resumo}

O artigo aborda o ativismo alimentar, propondo caracterizá-lo, no contexto brasileiro, em duas gerações. A primeira estaria relacionada à politização da alimentação e teria como característica principal as ações na esfera institucional e o predomínio de críticas éticas. A segunda se relacionaria à politização da comida e do comer, trazendo novos temas, atores e estratégias políticas, com tendência à convergência entre temas éticos e estéticos. Em seguida, o artigo discute a relação entre ativismo alimentar e consumo político, e aponta algumas limitações das pesquisas sobre o tema, além de apresentar dados que indicam uma especificidade da forma como o consumo político vem sendo incorporado pelos ativismos alimentares da América Latina. Embora presente em seus repertórios de ação, o consumo político não parece ser a principal estratégia dos ativismos alimentares da região. Estes movimentos concentram suas ações no fortalecimento do poder regulatório do Estado e na implementação de políticas públicas, além de esforçarem-se para não secundarizar o aspecto ético. Ao final, o artigo aponta que a Teoria das Práticas Sociais se apresenta como a mais promissora para abordar o consumo político alimentar.

Palavras-chave: Ativismo alimentar. Consumo político. Politização do consumo. América Latina.

\footnotetext{
Food activism and political consumerism - Two generations of food activism in Brazil Abstract

The article addresses food activism, proposing to characterize it, in the Brazilian context, in two generations. The first is related to the politicization of food. Their main features are actions in the institutional sphere and the predominance of ethic criticism. The second is related to the politicization of eaten. It brings new themes, actors and strategy, besides a convergence between ethic and aesthetic criticisms. Then, the article discusses the relation
}

\footnotetext{
${ }^{1}$ As reflexões discutidas neste artigo foram apresentadas em quatro eventos acadêmicos no ano de 2019, tendo recebido importantes contribuições de colegas e da audiência em geral. Agradeço, particularmente, aos colegas Renato Maluf (CPDA/UFRRJ) e Cátia Grisa (PGDR e PGDREDES/UFRGS). Ao primeiro pelas inúmeras conversas, incluindo aquelas em uma viagem de avião, e à segunda pela sugestão do ativismo institucional como uma estratégia central na implementação de políticas públicas de acesso aos alimentos. Agradeço também às minhas alunas e alunos, que têm sido excelentes interlocutores.
} 
between food activism and political consumerism, pointing to some limitations in the researchers and presenting data that indicate two specificities in the way political consumerism has been incorporated by food activisms in Latin America. Although present in these activisms' repertoires, political consumerism does not seem their main strategy. These movements concentrate their actions in strengthen the state regulatory power and fostering public policy, besides efforts to not neglect the ethic aspect. At the end, the article points to the Social Practice Theory as the most promising research line to addresses food political consumerism.

Keywords: Food activism. Political consumerism. Politicization of consumption. Latin America.

\section{Activismo alimentário y consumo político - Dos generaciones de activismo alimentario em Brasil}

\section{Resumen}

El artículo aborda el activismo alimentario, proponiendo caracterizarlo, en el contexto brasilero, en dos generaciones. La primera estaría relacionada a la politización de la alimentación y tendría como característica principal las acciones en la esfera institucional y el predominio de críticas éticas. La segunda se relaciona a la politización de la comida y del comer, trayendo nuevos temas, actores y estrategias políticas, con tendencia a la convergencia entre temas éticos y estéticos. Luego, el artículo discute la relación entre activismo alimentario y consumo político, y señala algunas limitaciones de las investigaciones sobre el tema, además de presentar datos que evidencian una especificidad en la forma como el consumo político viene siendo incorporado por los activismos alimentarios de América Latina. A pesar de estar presente en sus repertorios de acción, el consumo político no parece ser la principal estrategia de los activismos alimentarios de la región. Estos movimientos concentran sus acciones en el fortalecimiento del poder regulatorio del Estado y en la implementación de políticas públicas, además de esforzarse para no colocar el aspecto ético en segundo plano. Finalmente, el artículo apunta que la Teoría de las Prácticas Sociales se presenta como la más prometedora para abordar el consumo político alimentario.

Palabras clave: Activismo alimentario. Consumo político. Politización del consumo. América Latina

\section{Introdução}

A definição básica de ativismo alimentar gira em torno da ideia de discursos e ações de pessoas e grupos que se dedicam a elaborar uma crítica ao sistema agroalimentar visando torná-lo mais democrático, sustentável, saudável, ético com relação aos animais não-humanos, de melhor qualidade, que valoriza receitas tradicionais e outros temas correlatos (AZEVEDO, 2015, 2017; COUNIHAN e SINISCALCHI, 2014).

A noção de ativismo alimentar me chamou a atenção, inicialmente, por dois motivos. O primeiro é que este tipo de ativismo não pode ser considerado totalmente novo, afinal existe uma longa história de envolvimento de ativistas sociais e políticos com temas alimentares, como veremos abaixo.

O segundo motivo é que, na verdade, trata-se de um tema muito pesquisado, porém sem que os analistas recorram a esta noção. Inúmeros pesquisadores vêm se dedicando à compreensão de movimentos sociais que se organizam em torno de temas alimentares, desde o direito humano à alimentação, a soberania e segurança 
alimentar e nutricional e o combate à fome a iniciativas em torno de agriculturas de base ecológica e movimentos como o fair trade, o Slow Food e os diversos tipos de redes alimentares alternativas, sem recorrer, no entanto, à noção de ativismo alimentar ${ }^{2}$. Trata-se de uma linha de pesquisa em plena efervescência e com a qual pretendo contribuir com este artigo.

Estranhamente, Counihan e Siniscalchi (2014), organizadoras da coletânea "Food Activism - Agency, democracy and economy", numa abordagem claramente etnocêntrica, excluem do que chamam de ativismo alimentar, os movimentos de combate à fome, alegando tratar-se de tema muito vasto e que mereceria um livro a parte. Ao contrário das autoras, e considerando o contexto latino-americano, e certamente o de outras regiões do Sul Global, prefiro refletir sobre as diversas expressões do ativismo alimentar, incluindo as lutas contra a fome, e suas transformações recentes.

Na primeira seção deste artigo, discuto algumas das transformações pelas quais penso que o ativismo alimentar vem passando no contexto brasileiro, o que me levou a caracterizá-lo em duas gerações: a primeira estaria relacionada à politização da alimentação e a segunda se relacionaria ao que vou chamar de politização da comida ${ }^{3}$ e do comer.

Em seguida, discuto a relação entre ativismo alimentar e consumo político ou, como prefiro, com os processos de politização do consumo, tema que vem me ocupando há algum tempo. Na mesma seção, aponto brevemente algumas limitações e avanços teórico-metodológicos das pesquisas sobre consumo político e apresento alguns dados que indicam o que penso ser uma especificidade da forma como o consumo político vem sendo incorporado pelos ativismos alimentares da América Latina.

Nas considerações finais, discuto brevemente estas especificidades à luz da literatura mais recente sobre consumo político e indico uma linha de pesquisa que me parece mais promissora para abordar o consumo político alimentar.

\section{Da politização da alimentação à politização da comida e do comer - Duas gerações de ativismo alimentar no Brasil}

Parto do argumento de que o campo interdisciplinar de reflexões sobre a alimentação como campo político vem se transformando e passando por um processo de expansão e transbordamento, da esfera institucional para a esfera privada, cotidiana e rotineira da comida e do comer.

Assim, penso que poderíamos identificar uma primeira geração de ativismo alimentar que politiza a alimentação e teria como características principais a centralidade das ações na esfera institucional do Estado, além de ações filantrópicas

\footnotetext{
${ }^{2}$ Em uma rápida busca no Google Scholar, notamos que tal noção começou a aparecer nos debates acadêmicos brasileiros somente a partir de 2013, e encontramos apenas três pesquisadores brasileiros que a utilizam explicitamente: Elaine de Azevedo (UFES), Daniel Coelho (Unimontes) e Potira Preis (UNISC).

${ }^{3}$ Valho-me aqui da conhecida diferença proposta por DaMatta (1986, p.56) entre alimentação e comida, em que a última refere-se à apropriação dos alimentos pela cultura: "Comida não é apenas uma substância alimentar, mas é também um modo, um estilo e um jeito de alimentar-se. E o jeito de comer define não só aquilo que é ingerido, como também aquele que o ingere".
} 
e assistencialistas, com predomínio de críticas éticas e demandas distributivas, como o combate à fome e à desnutrição, a distribuição e o acesso aos alimentos, a soberania e a segurança alimentar e nutricional e o direito humano à alimentação. Os principais porta-vozes desta geração de ativismo alimentar eram ativistas da área de saúde (médicos e nutricionistas), economistas, gestores públicos, cientistas políticos e organizações assistencialistas, incluindo as de cunho religioso. Questões relativas ao consumo e ao consumidor não tinham lugar nesta geração.

No caso brasileiro, o marco mais importante para o surgimento de um ativismo social em torno da alimentação são as reflexões pioneiras de Josué de Castro, nos anos 1940, mostrando que a fome e a pobreza são uma questão política, e não apenas de saúde pública ou de assistência social. Josué de Castro mostrou que a fome, até então um tabu no Brasil e em muitas partes do mundo ("silêncio premeditado pela própria alma da cultura”, nas palavras de Josué), era expressão de um modelo político e econômico que perpetuava a pobreza (CASTRO, 2005; LEÃO e MALUF, 2012; VASCONCELOS, 2008). Com isso, inspirou diversos movimentos sociais e políticos que, numa trajetória de avanços e retrocessos (PELIANO, 2010), lutaram pela implementação de uma série de políticas públicas para conter a pobreza e reduzir a fome e a desnutrição, como o salário mínimo, os primeiros restaurantes populares e a "Campanha da Merenda Escolar", criada em 1955 por Juscelino Kubitscheck, e que mais tarde daria origem ao Programa Nacional de Alimentação Escolar (PNAE), para citar apenas alguns exemplos.

$\mathrm{Na}$ história brasileira recente, o caso mais marcante de mobilização social em torno da alimentação é a "Ação da Cidadania contra a Fome, a Miséria e pela Vida", organizada pelo sociólogo Herbert de Souza, em 1993, e que existe até os dias atuais ${ }^{4}$. Com o slogan "quem tem fome, tem pressa", a campanha foi lançada a partir do "Movimento pela Ética na Política", e tinha como objetivo a mobilização de cidadãos insatisfeitos com a demora do Estado brasileiro em enfrentar o problema da fome e da miséria no país. A campanha foi pensada, portanto, como uma ação concreta que estimulava a participação de voluntários na doação de gêneros alimentícios, notadamente os não-perecíveis, mas também na mobilização para pressionar os governos para construir e melhorar as políticas públicas voltadas para a alimentação.

Dentro desse escopo, poderíamos citar diversos outros exemplos de mobilizações populares em torno da melhoria da alimentação e do combate à fome, envolvendo críticas aos sistemas de produção e abastecimento agroalimentar (baseados em latifúndios, concentração de terras, maquinário e insumos agrícolas, em especial os agrotóxicos) e lutas por políticas públicas de alimentação e nutrição. Vale destacar, no Brasil, a construção participativa da Política Nacional de Segurança Alimentar e Nutricional, que combinou a mobilização de organizações e redes sociais (LEÃO e MALUF, 2012) com ativismo institucional ${ }^{5}$ (CAYRES, 2017). Um dos resultados de tais lutas, o SISAN (Sistema Nacional de Segurança Alimentar e

\footnotetext{
${ }^{4}$ https://www.acaodacidadania.com.br/. Acesso em 19 de abril de 2020.

${ }^{5}$ Cayres (2017) chama de ativismo institucional as ações de atores governamentais comprometidos, pessoal e institucionalmente, com as pautas dos movimentos sociais, atuando "por dentro do Estado" na pressão para implementar mudanças nas políticas públicas.
} 
Nutricional), pode ser considerado um exemplo bem sucedido de politização da alimentação ${ }^{6}$.

Interessante mencionar que, nesse breve resgate da primeira geração de ativismo alimentar, observa-se que este passou por um processo de ampliação, incluindo, paulatinamente, diversos outros temas correlatos à alimentação e à fome, como a reforma agrária, a autonomia dos pequenos agricultores, a crítica à agricultura industrial e, mais recentemente, a ideia de alimentação adequada ${ }^{7}$ e a criação de mercados para a produção da agricultura familiar, incluindo os mercados institucionais.

No entanto, se para responder e buscar soluções para os problemas da fome e desnutrição as políticas públicas são essenciais, valendo mencionar as experiências bem-sucedidas no Brasil de compras institucionais e dos conselhos de SAN, uma abordagem puramente institucional da alimentação como campo político, predominante no que estou chamando de primeira geração de ativismo alimentar, já não parecia mais suficiente, incapaz de capturar o vasto leque de demandas, estilos de vida e conexões entre a produção, a distribuição e o consumo de alimentos.

Goodman, Dupuis e Goodman (2012) chamam a atenção para o ressurgimento, no início do século $\mathrm{XXI}$, de uma miríade de organizações sociais e grupos de protesto que, estimulados pelos movimentos ambientalistas e pela ocorrência de riscos alimentares relacionados à produção industrial, renovam os ativismos sociais em torno da alimentação e retomam temas e mobilizações políticas dos anos 60. Com isso, diversos movimentos em prol de formas alternativas de agricultura explodem no Brasil e no mundo, com destaque para a ampla mobilização em torno da agroecologia e para as experiências de economia solidária, feiras "direto com o produtor" e construção de redes de produção e consumo. Além disso, surgem e crescem movimentos que propõem estilos de vida alternativos, como o veganismo e outras propostas mais recentes como freeganismo, locavorismo, crudivorismo, flexitarianismo e climaterianismo.

Paralelamente, diversas transformações nos sistemas agroalimentares, incluindo a centralidade dos supermercados nas cadeias globais (GUIVANT, SPPARGAREN e RIAL, 2010), contribuíram para lançar luz sobre o papel dos consumidores em mercados que passam a se orientar, cada vez mais, pela "demanda". Tudo isso impulsionou o surgimento de novas dinâmicas relacionadas à valorização da qualidade e da origem dos alimentos (relocalização), fazendo proliferar uma série de redes e movimentos em torno do comércio justo e de alimentos orgânicos, agroecológicos, locais e artesanais, voltados para a valorização da produção de pequenos agricultores (GOODMAN, 2003) e enfatizando demandas por reconhecimento (WILKINSON, 2010).

\footnotetext{
${ }^{6}$ Muito embora tais lutas venham amargando fracassos no Brasil pós-2016.

7 Por limite de espaço, não será possível refletir aqui sobre o que parece ter sido um importante papel dos movimentos pelo Direito Humano à Alimentação no tensionamento da primeira geração de ativismo alimentar, trazendo para o debate sobre SAN, de um lado, uma crítica ao nutricionismo e, de outro, as abordagens antropológicas sobre cultura alimentar, realçando a ideia "direito de escolha do que comer" e a necessidade de qualificar melhor o que seria uma "alimentação adequada".
} 
Os movimentos ambientalistas, certamente, contribuíram para a construção de uma crítica à insustentabilidade dos sistemas agroalimentares, favorecendo propostas de agricultura alternativa e de formas de alimentação que não produzissem danos ambientais, em especial mudanças climáticas.

A “Crise da Vaca louca”, ocorrida na Europa em meados dos anos 80, é o exemplo sempre citado quando se aborda a emergência da preocupação pública com os riscos para a saúde, para o meio ambiente e para os pequenos agricultores associados aos sistemas agroalimentares industriais (HALKIER, 2004; LIEN e NERLICH, 2004; PORTILHO, CASTAÑEDA e CASTRO, 2011; SANTOS JUNIOR, CASTRO e PORTILHO, 2013). O advento dos organismos geneticamente modificados soma-se a este contexto de percepção de risco, levando a mobilizações em diversos países (MOTTA, 2018). No caso brasileiro, vale mencionar três exemplos: a "Campanha Por um Brasil Livre de Transgênicos", organizada por uma rede de movimentos sociais que incluiu ambientalistas, grupos de agricultura alternativa e movimentos de consumidores (FREITAS, 2011); as lutas contra os agrotóxicos, particularmente aquelas organizadas sob o guarda-chuva da "Campanha Permanente Contra os Agrotóxicos e Pela Vida"; e a "Aliança pela alimentação Saudável e Adequada", uma rede de organizações da sociedade civil que tem por objetivo desenvolver e fortalecer ações coletivas para a realização do Direito Humano à Alimentação Adequada.

O caso icônico dessa nova expressão de ativismo alimentar é o movimento Slow Food. Criado na Itália em 1986, e espalhando-se rapidamente para diversos países, o Slow Food destacou-se por seu caráter pioneiro de crítica estética à padronização da alimentação e a uma forma fast de comer, típicas da chamada modernização alimentar (POULAIN, 2006), revalorizando o prazer hedonista dos cinco sentidos envolvidos na comida e no comer ${ }^{8}$. Paulatinamente, passa a incorporar elementos da crítica ética, próprios dos movimentos sociais de perfil clássico e da primeira geração de ativismo alimentar, até chegar ao seu slogan atual: "bom, limpo e justo" (OLIVEIRA, 2014). Na análise de Barbosa (2016), este e outros exemplos indicam a ocorrência de um processo de "eticização" da estética e, ao mesmo tempo, de "estetização" da ética. Com isso, o Slow Food pode ser visto como pioneiro também na convergência entre ética e estética no campo da alimentação, da comida e do comer, temas que ganharam protagonismo e visibilidade, inspirando outras experiências e inaugurando a participação dos chefs de cozinha no ativismo alimentar (BARBOSA, 2009; BARBOSA, 2016; GUILHERME, 2016; GUILHERME; PORTILHO, 2018; PORTILHO et al., 2018; ZANETI; SCHNEIDER, 2016).

Um exemplo brasileiro recente que mostra como a comida vem aos poucos ganhando centralidade em relação ao alimento e à alimentação é a forma com que passou a fazer parte das prescrições nutricionais do Estado, o que pode ser verificado no Guia Alimentar para a população Brasileira, publicado em 2006, pelo Ministério da Saúde (BRASIL, 2014). Este guia tem sido considerado um avanço nos

\footnotetext{
${ }^{8}$ Estudando o Slow Food, Oliveira (2014) lembra, acertadamente, que o consumismo moderno é baseado, segundo Campbelll (2001), em uma ética hedonista imaginativa, que rompe com os cinco sentidos, embora o prazer de comer não tenha desaparecido completamente. O Slow Food, ao contrário, resgatou o hedonismo sensorial, valorizando os cinco sentidos do comer.
} 
debates sobre nutrição exatamente por valorizar, não mais os nutrientes contidos nos alimentos, mas a comida e a comensalidade, adotando uma clara crítica aos alimentos processados e ultra processados produzidos pela indústria alimentar. Este e outros exemplos mostram uma mudança na postura do Estado, que passa a se posicionar como árbitro do "comer correto" (BARBOSA, 2016). Slogans como "comida de verdade" e "comer é um ato político" tornaram-se recorrentes entre os ativistas alimentares da segunda geração.

Assim, a alimentação politizada no âmbito de suas conexões com um modelo político e econômico que perpetua a pobreza e a fome, com foco nas críticas éticas e nas demandas por redistribuição, passou a ser politizada também quanto a sua forma de produção e consumo, levando ao surgimento de uma segunda geração de ativistas alimentares, que politizam a comida e o comer, fazendo convergir questões éticas e estéticas (BARBOSA, 2016; WILKINSON, 2010). Coisas mundanas, como o arroz-com-feijão de todo dia, e práticas rotineiras, como o comer, tornam-se alvo de múltiplas contestações políticas, tornando-se objeto de disputas (BARBOSA, 2009; HALKIER, 2019; LIEN; NERLICH, 2004).

Há muito, ainda, a ser pesquisado sobre o que estou chamando de segunda geração de ativismo alimentar, mas como reflexão inicial, aponto o fato de que esta, ao extrapolar a esfera institucional, transborda-se, de um lado, para os movimentos em torno de formas alternativas de agricultura e, de outro, para a esfera privada e rotineira do consumo alimentar mundano. Isso daria lugar ao surgimento de uma infinidade de novos temas, novos atores e novas estratégias políticas.

Com relação aos temas, a segunda geração de ativismo alimentar inclui, como já mencionado, a pauta ambiental e climática, questões da sociobiodiversidade, a "causa rural" (reforma agrária, modo de vida camponês etc.), os riscos da produção alimentar convencional para a saúde (agrotóxicos, alimentos processados e transgênicos), o bem-estar animal e diversas questões de ordem estética, elaboradas principalmente na esfera do consumo (BARBOSA, 2016; PORTILHO; BARBOSA, 2018; WILKINSON, 2010). Sobre este última tópico, ganham ênfase os temas ligados à valorização do sabor, da cultura alimentar (receitas e ingredientes tradicionais, técnicas de preparo etc.) e do território, além do cozinhar e da sociabilidade em torno da mesa, o que implicou no reposicionamento da cozinha na arquitetura das casas, na ampliação da cultura material relacionada ao comer e no desenvolvimento do capital gastronômico (BARBOSA, 2016, 2009; MENASCHE, 2015; MENEZES; CRUZ, 2018; WILKINSON; NIEDERLE; MASCARENHAS, 2016).

Quanto aos atores, destaco quatro grupos, além daqueles da primeira geração: (1) os ativistas sociais e ambientais em torno da agroecologia e outras formas de produção alternativa e sustentável; (2) o consumidor e suas organizações (defesa dos direitos do consumidor, cooperativas e grupos de compras), (3) os chefs de cozinha e (4) os movimentos sociais do campo.

O primeiro grupo é, sem dúvida, o mais citado, havendo uma infinidade de pesquisas dedicadas ao mesmo, em especial no que se refere ao movimento agroecológico e seus atores (BRANDENBURG; LAMINE; DAROLT, 2015; CHARÃOMARQUES; SCHMITT; OLIVEIRA, 2017).

Com relação aos consumidores, a maioria dos pesquisadores brasileiros dedicados aos estudos agroalimentares já os consideram, junto com suas 
organizações, como atores dos mercados e como ativistas de causas alimentares (PORTILHO, 2009; PORTILHO; BARBOSA, 2018; DAROLT, 2013; NIEDERLE; WESZ JUNIOR, 2018), incluindo, portanto, o que costumo chamar de "agenda da mesa da cozinha" e caminhando em direção à simetria entre produção e consumo proposta por Goodman e Dupuis (2002).

Os chefs de cozinha começaram a aparecer, recentemente, em algumas pesquisas brasileiras que destacam seu novo papel como ativista alimentar, impulsionando uma tendência da gastronomia contemporânea em valorizar e utilizar produtos singulares (orgânicos, artesanais, tradicionais, locais e provenientes da agricultura familiar), especialmente por seu sabor e qualidade, mas também pelo seu compromisso social e pela busca de identidade e reconhecimento profissional (GUILHERME, 2016; GUILHERME; PORTILHO, 2018; PORTILHO et al., 2018; ZANETI e SCHNEIDER, 2016).

Os movimentos sociais do campo e cooperativas de pequenos agricultores também têm surgido na cena do ativismo alimentar (FREITAS, 2011; TANAKA; PORTILHO, 2019; NIEDERLE; WESZ JUNIOR, 2018), conforme será abordado abaixo.

Finalmente, com relação às estratégias políticas da segunda geração de ativistas alimentares, o principal destaque, me parece, deve ser dado, de um lado, à promoção de diversos modelos de cadeias alimentares curtas, que (re)aproximam pequenos produtores e consumidores (BENINI, 2018; CASSOL; SCHNEIDER, 2015; DAROLT, 2013; GOODMAN; DUPUIS; GOODMAN, 2012; PORTILHO; FERREIRA, 2019; PREISS, 2017), e, de outro, e como pré-requisito da primeira, ao consumo político, uma das formas mais inovadoras e polêmicas de pressão política, que será abordado abaixo (BOSTRÖM; MICHELETTI; OOSTERVEER, 2019; HALKIER, 2019; STOLLE; HOOGHE; MICHELETTI, 2005).

No entanto, temas éticos e distributivos não saíram de cena. Se o Brasil conseguiu sair do Mapa da Fome da ONU em 2014 (FAO; IFAD; WFP, 2014; IPEA, 2019), o tema tem voltado ao debate público, assim como as campanhas de doação para populações vulneráveis, especialmente a partir de 2016, com o desmonte de uma série de políticas sociais relacionadas à segurança alimentar e nutricional, redução da pobreza e compras institucionais ${ }^{9}$. Além disso, nos dias atuais, à fome e à carência nutricional soma-se uma preocupação com o sobrepeso e a obesidade. Isso confirma que o que estou chamando de segunda geração do ativismo alimentar brasileiro caracteriza-se mais por uma ampliação do que por uma substituição do ideário anterior.

Na próxima seção trago à tona algumas reflexões preliminares sobre a noção de ativismo alimentar para, em seguida, discutir sua relação com o consumo político, particularmente no contexto da América Latina.

\footnotetext{
${ }^{9}$ Escrevo em meados do segundo mês de distanciamento social por causa do coronavírus enquanto observo a expansão dos pedidos de doação de alimentos e de ajuda financeira para entidades assistencialistas, que chegam através de redes sociais.
} 


\section{Ativismo alimentar e consumo político na América Latina - Reflexões iniciais}

O consumo alimentar, que sempre foi alvo de contestações morais pelo fato de ser "incorporado" (FISCHLER, 2010; POULAIN, 2006), tem sido um dos casos mais pesquisados de consumo político (HALKIER, 2019), associado a diversas "causas", como sustentabilidade, mudanças climáticas, justiça social, desigualdades, relações trabalhistas, reforma agrária e bem-estar animal (PORTILHO; BARBOSA, 2018).

O que hoje é caracterizado como consumo político tem uma longa história de envolvimento com temas alimentares. O caso mais antigo de consumo político, correntemente citado nos estudos sobre o tema, envolveu protestos de colonos ingleses na "América" de 1776 contra os altos impostos do governo britânico e o lançamento ao mar de um carregamento de chá, no Porto de Boston, acontecimento chave na história da independência dos EUA. Outros exemplos sempre citados, e que também envolvem temas alimentares, são o famoso boicote à multinacional Nestlé, nos anos 70 do século XX, contra a propaganda de seus produtos como substitutos do leite materno, o boicote à África do Sul, nos anos 80 , em protesto contra o Apartheid, e diversos boicotes ao McDonald's contra a padronização do fastfood e as condições de trabalho de seus empregados. $O$ próprio termo "consumo político" foi cunhado na Europa, em meados dos anos 90, na onda de dois protestos, um deles em torno de um tema alimentar ${ }^{10}$ : o boicote ao vinho francês como oposição aos testes nucleares conduzidos pela França (HALKIER, 2019; HALKIER; HOLM, 2008; JAGER, 2019; SASSATELLI, 2006; STOLLE; HOOGHE; MICHELETTI, 2005).

Por isso, não foi surpresa notar que, ao levantar dados sobre a percepção e uso do consumo político por movimentos sociais latino-americanos para uma pesquisa recente (PORTILHO; MICHELETTI, 2018), a maioria dos casos tratava de temas alimentares, como mostrarei abaixo. De fato, a alimentação, a comida e o comer têm sido considerados os melhores exemplos de temas que mobilizam consumidores (BOSTRÖM; MICHELETTI; OOSTERVEER, 2019).

A definição usual de consumo político relaciona-se à percepção e uso efetivo do consumo (poder de compra no mercado) como forma de pressão política para promover mudanças sociais. Embora o consumo político também possa ter governos como alvo (caso dos boicotes à França e à África do Sul, citados acima), trata-se, na maior parte das vezes, de uma forma de engajamento político na esfera do mercado (market-oriented engagements), que se manifesta na escolha de marcas, produtos, produtores e/ou varejistas baseada em considerações políticas, éticas e/ou ambientais. Nesse sentido, o consumo político pode ser analisado em associação com diversas iniciativas que Gendron, Bisaillon e Rance (2009) chamam de novos movimentos sociais econômicos, como economia solidária, comércio justo e redes alimentares alternativas, em que o mercado, mais do que o Estado, passa a ser alvo de uma ação política que visa a reapropriação da economia a partir dos valores destes movimentos.

\footnotetext{
${ }^{10} \mathrm{O}$ segundo evento foi o boicote à multinacional Shell por causa de suas negligências ambientais e de direitos humanos.
} 
Stolle, Hooghe e Micheletti (2005, p. 246) consideram que, independentemente dos consumidores agirem de forma individual ou coletiva, suas escolhas no mercado "refletem um entendimento dos produtos materiais como enraizados em um complexo contexto social e normativo, que pode ser chamado de política por trás dos produtos". Esse fato faz com que o consumo político seja associado a uma forma de desfetichização da mercadoria, valorizando e explicitando as relações sociais de produção.

Com isso, a fronteira entre esfera pública e privada, cidadão e consumidor, política e economia deixa de ser bem demarcada. Neste contexto, produção e consumo não são considerados meros assuntos privados sobre negócios e preferências, baseados em análises de custo-benefício. Ao contrário, são percebidos como estando relacionados a eventos políticos, questões éticas, impactos ambientais e direitos humanos, entre tantos outros temas.

Já é consenso entre os pesquisadores da área que o consumo político se manifesta de quatro formas básicas. O boicote, considerado "consumo político negativo", é a recusa da compra motivada por preocupações políticas, éticas e/ou ambientais. O buycott, por sua vez, é uma forma de "consumo político positivo", por referir-se a compras efetivas como forma de favorecer ou premiar marcas, produtos, produtores e/ou varejistas por seus compromissos políticos, éticos e/ou ambientais. A terceira forma são as ações discursivas ou comunicativas, que envolvem protestos, críticas e manifestações públicas (incluindo "falar bem" ou "falar mal") pelas mesmas razões. A quarta e última forma de consumo político são as chamadas políticas de estilos de vida, que envolvem mudanças mais profundas em práticas cotidianas e tendem a incluir as três anteriores. Além disso, as ações de consumo político variam das formas mais confrontacionais às mais cooperativas. Se boicotes e ações discursivas são considerados mais confrontacionais, os buycotts dependem de estratégias cooperativas com produtores e com esquemas de regulação e rotulagem, muitas vezes comandados por governos. As políticas de estilos de vida conjugariam as duas formas, envolvendo revisões de práticas da vida diária, que podem se desenvolver em compromissos profundos e mudanças radicais, como no caso do veganismo (BOSTRÖM; MICHELETTI; OOSTERVEER, 2019).

No entanto, desde 2005, quando foi publicado o artigo seminal de Dietlind Stolle, Marc Hooghe e Michele Michelleti, intitulado "Politics in the supermarket: Political consumerism as a form of political participation" (STOLLE; HOOGHE; MICHELETTI, 2005), a literatura sobre o assunto vem avançando e levantando questões instigantes sobre os limites do consumo político e sua relação com as complexidades das cadeias de produção e consumo globalizadas. O foco inicial nas ações do consumidor individual no mercado vem dando lugar a preocupações com a relação entre diferentes atores, as formas de ação, os movimentos organizados e o contexto político e institucional (BOSTRÖM; MICHELETTI; OOSTERVEER, 2019).

Os autores têm optado por uma compreensão mais nuançada, que mantém as quatro principais formas de ação mencionadas, mas realça pré-requisitos estruturais como, por exemplo, as redes e movimentos sociais, as configurações institucionais (certificação e rotulagem, por exemplo), a cultura política, as trocas internacionais e o papel (facilitador ou não) do Estado, estudando o consumo 
político como parte de relações de governança transnacionais (ARIZTIA et al., 2013; ARIZTIA et al., 2016; BOSTRÖM; MICHELETTI; OOSTERVEER, 2019).

Monticelli e Della Porta (2019) propõem pensar o consumo político como "ações individuais coletivizadas", enfatizando, por exemplo, as redes alimentares alternativas. Já Dubuisson-Quellier (2019), a partir de uma abordagem da sociologia econômica, propõe que ações de consumo político, mesmo com limitado efeito em produzir mudanças sociais, levam à produção e circulação de recursos materiais, normativos e simbólicos, fazendo surgir uma economia moral que desafia as práticas econômicas vigentes.

Além disso, pesquisadores têm estudado o desenvolvimento de novos arranjos de governança, especialmente no caso dos buycotts, como as diversas experiências inovadoras de construção de sistemas de certificação, muitas vezes ocorrendo fora da esfera do Estado. Atores governamentais, no entanto, também aparecem em diversos estudos como um "consumidor institucional", como é o caso das experiências de compras públicas (ARIZTIA et al., 2013).

Outra forma clássica de estudar o consumo político é a partir de iniciativas promovidas por movimentos sociais e redes de produtores e consumidores, que mobilizam consumidores para agirem através do consumo em prol de diversas causas.

Diani (2019) e Forno (2019) consideram o consumo político como uma ferramenta ou método para organizar e mobilizar pessoas e não um projeto político propriamente dito. Os autores mostram que o uso desta ferramenta por movimentos sociais tem sido uma forma de ampliação de suas estratégias de luta, criando e reforçando laços locais e globais de solidariedade que ajudariam a implementar seus projetos políticos. Forno (2019) analisa exemplos em que movimentos sociais usam o consumo político para se reposicionar, criando um novo imaginário social e novas dimensões na política.

Finalmente, os estudos mais recentes se movem de uma perspectiva da ação individual no mercado, informada por valores e reflexividade, em direção à incorporação das contribuições da Teoria das Práticas Sociais, que defende que um melhor entendimento das dinâmicas da vida cotidiana contribui para uma compreensão mais refinada do consumo político alimentar (HALKIER, 2019; HALKIER; HOLM, 2008; LÓPEZ-PÉREZ; GUERRERO-ERAZO, 2017; OOSTERVEER et al., 2019).

Considerando a emergência no Brasil de uma segunda geração de ativismo alimentar, descrita acima, que impulsiona novas reflexões e práticas relativas à alimentação, à comida e ao comer, politizando a produção e o consumo de alimentos, pareceu-me coerente pensar que haveria ampla incorporação da estratégia do consumo político por estes movimentos e ativistas, a exemplo do que vem acontecendo nos países do Norte global, conforme estudo de Halkier (2019).

No entanto, minhas pesquisas recentes junto com alunos e colegas do Grupo de Estudos do Consumo me levaram a apontar o que parecem ser duas especificidades do ativismo alimentar da América Latina. Em primeiro lugar, o consumo político não é sua principal estratégia de ação. Em segundo lugar, haveria, de fato, uma convergência entre questões éticas e estéticas, mas, ao mesmo tempo, um esforço para não secundarizar o aspecto ético. Para chegar a essas duas asserções, cito a seguir dois exemplos. 
O primeiro exemplo vem de dados obtidos de diversas formas, entre elas minha experiência, durante o período 2009 a 2013, como membro acadêmico de uma rede latino-americana de ONGs que se dedicava a refletir e propor ações de consumo sustentável na região ${ }^{11}$. Em 2017, realizei entrevistas e levantei dados secundários e documentais sobre organizações sociais de cinco países da América Latina (México, Argentina, Peru, Chile e Brasil), além de uma entrevista com uma pessoa do Escritório para a América Latina e Caribe da Consumers International ${ }^{12}$, com vistas à elaboração de um artigo sobre consumo político na América Latina (PORTILHO; MICHELETTI, 2018). As organizações pesquisadas foram: El Poder del Consumidor (México); Educar Consumidores (Colômbia); Instituto de Defesa do Consumidor - Idec (Brasil) e Associação Peruana de Consumidores e Usuários - Aspec (Peru).

Todas estas organizações se envolveram em ações contra a indústria de refrigerantes por seus malefícios à saúde e usaram as quatro formas de consumo político, mas sua estratégia principal se concentrou em ações para influenciar parlamentares no sentido de aumentar os impostos sobre essas bebidas e criar rotulagem informativa sobre seu alto teor de açúcar. Todos os entrevistados afirmaram que ações de boicote não são suas principais ferramentas e não usam esse termo de forma explícita (PORTILHO; MICHELETTI, 2018).

A pessoa do Idec entrevistada por mim, por exemplo, informou que considera importante a ação individual dos consumidores, mas criar e fortalecer uma boa configuração institucional para conformar suas escolhas e ações é a principal estratégia da organização. Além disso, o Idec não faz campanhas citando negativamente o nome de empresas, o que seria um estímulo a ações de boicote.

Um caso relatado pela Aspec é interessante e merece um breve relato. Em 2017, houve um escândalo envolvendo os produtos lácteos da empresa Glória, que usavam a palavra "leite" na embalagem, junto com imagens de uma vaca, embora fossem produtos modificados e não leite propriamente dito. A Aspec lançou uma campanha chamada "La leche que no es leche" e concentrou esforços para proibir a palavra leite e a imagem de vacas nas embalagens destes produtos. A Aspec usou as quatro formas de consumo político, mas colocou mais ênfase na pressão aos governos para uma regulação mais restritiva do setor, incluindo a regulação de anúncios, rótulos e embalagens. Minha entrevistada afirmou que, no caso desta campanha, houve um movimento de boicote, e as pessoas, em geral, pararam de comprar os produtos desta marca. Mas ela chama atenção para o fato de que "a Aspec não usa esta palavra [boicote] porque no Peru ela é considerada uma 'palabra muy gringa'. Peruanos não lidam bem com ela, mas as pessoas deixam de comprar, quando casos como este acontecem".

\footnotetext{
${ }^{11}$ Esta rede se formou a partir da iniciativa do Projeto PERL (The Partnership for Education for Responsible Living), uma parceria entre a Consumer Citizenship Network (CCN) e diversas instituições acadêmicas, organizações da sociedade civil e instituições governamentais europeias, sob os auspícios e com financiamento da European Commission, UNESCO, UNEP, The Marrakech Task Force for Education for Sustainable Consumption, The Marrakech Task Force for Sustainable Lifestyles e a Hedmark University College/Noruega. https://www.perlprojects.org/. Acesso em 19 de abril de 2020.

${ }^{12}$ A Consumers International é uma associação mundial de grupos e organizações de defesa de direitos dos consumidores, congregando cerca de 200 membros de mais de 100 países. https://www.consumersinternational.org/. Acesso em 19 de abril de 2020.
} 
A pessoa da Consumers International entrevistada por mim chamou a atenção para como as "ideias vindas do Norte" (especialmente da ONU e das ONGs globais) são recebidas na América Latina, afirmando que os movimentos sociais da região "não gostam de conceitos como consumo político, embora eles mobilizem os consumidores para pressionar mercados e governos". Para ela, estes movimentos sociais consideram que a noção de consumo político "está em desacordo com as categorias mais convencionais e ideológicas de cidadão e trabalhadores", e afirma que "algumas ONGs latino-americanas com ações mais globais usam estas ideias, mas aquelas de ação mais enraizada localmente não, pois seu principal esforço está na mudança de leis, na construção de políticas públicas e no fortalecimento do poder regulatório do Estado".

A principal forma de ativismo destas organizações, portanto, são as ações de lobby e advocacy, visando influenciar parlamentares e governos e construir políticas públicas, mantendo a pressão política na esfera do Estado, e não do mercado. Ao que parece, movimentos sociais latino-americanos não confiam na efetividade de ações políticas no mercado, e consideraram que a mobilização individual é secundária em relação às ações coletivas.

Estes dados corroboram os achados de Ariztia e seus colegas (2016), que mostraram que a noção de consumo ético não é bem compreendida entre chilenos e brasileiros, exceto por aqueles consumidores com nível de renda mais alto e com experiências de viagens internacionais. Além disso, os autores citados, assim como Barbosa et al. (2014), mostraram que tanto chilenos quanto brasileiros têm dúvidas se suas compras individuais podem realmente levar a mudanças sociais.

Meu segundo exemplo vem de reflexões em conjunto com uma de minhas orientandas, que nos levaram a pesquisar a percepção e o uso do consumo político por movimentos sociais brasileiros de perfil clássico (TANAKA; PORTILHO, 2018; TANAKA, 2019; TANAKA; PORTILHO, 2019). Analisamos o caso de dois movimentos sociais do campo que, recentemente, incorporaram a estratégia do consumo político, construindo alianças com consumidores urbanos através da organização de formas alternativas de comercialização de alimentos: o Movimento dos Trabalhadores Rurais Sem Terra (MST) e o Movimento dos Pequenos Agricultores (MPA). Embora com diferenças significativas nas identidades sociais e nas formas de luta mobilizadas por eles, ambos passaram a incorporar, em seus discursos e ações, estratégias identificadas com o consumo político, além de mobilizarem temas relativos à alimentação, à comida e ao comer.

O MST, por exemplo, que já tinha em seu histórico experiências pontuais de comercialização de alimentos produzidos em seus assentamentos, inaugurou uma série de lojas Armazém do Campo em cinco cidades brasileiras, além de organizar feiras para comercializar "alimentos da reforma agrária", com destaque para a Feira Nacional da Reforma Agrária, em São Paulo/SP, o que se configura como um estímulo a ações de buycott (TANAKA; PORTILHO, 2018).

De forma semelhante, a comercialização de "alimentos da agricultura camponesa" passou a ocupar o núcleo das ações do MPA a partir dos anos 2000, através primeiro da entrega de cestas de alimentos e, posteriormente, da abertura de um espaço chamado Raízes do Brasil, em 2017, na cidade do Rio de Janeiro/RJ. Trata-se de um local voltado para a comercialização de alimentos (feiras e entrega de cestas), além de contar com um restaurante que serve "almoço camponês", 
pousada e espaço para eventos, sempre com o apelo aos "alimentos da agricultura camponesa". O MPA refere-se, nestes espaços e ações, aos "cestantes", ao "povo brasileiro" e aos "trabalhadores urbanos", evitando usar a categoria consumidor (TANAKA, 2019; TANAKA; PORTILHO, 2019).

Estes dois movimentos sociais do campo, citados brevemente, conjugam temas da primeira e da segunda geração de ativismo alimentar em seus discursos e ações, associando as críticas ética e estética, o que fica ainda mais claro ao observarmos dois dos slogans mais usados por eles: "Comida de verdade no campo e na cidade" e "comer é um ato político". É certo também que, a partir de tais iniciativas, estes movimentos buscam, para além da comercialização, politizar o consumo e criar alianças com consumidores urbanos para fortalecer suas pautas (TANAKA, 2019; TANAKA; PORTILHO, 2019).

Como se pode notar nos dois exemplos acima, e conforme já apontado em estudos anteriores (MICHELETTI; STOLLE, 2014; PORTILHO; MICHELETTI, 2018; TANAKA e PORTILHO, 2019), mesmo incorporando o consumo político em seus repertórios de luta, estes movimentos sociais o fazem de forma ambígua, com diversas críticas e com certo desconforto com a ideia do consumidor como categoria política. Frequentemente, dão preferência a categorias mais usuais e, em muitos casos, priorizam as formas convencionais de pressão política na esfera institucional do Estado, esforçando-se para não secundarizar o aspecto ético.

Dentre as diversas explicações para estas ambiguidades e desconfortos, destaco as análises de Frank Trentmann, que mostram que a resiliência de identidades e categorias ligadas à luta de classes e ao mundo do trabalho acaba fazendo com que o consumidor permaneça ausente dos discursos, mesmo quando o consumo político é incorporado enquanto um repertório de ação (TRENTMANN, 2004, 2007, 2006).

As ambiguidades e desconfortos com relação ao consumo político entre os ativistas estudados podem ser compreendidas, também, a partir da própria literatura sobre o tema, que tem destacado, como mencionado, a necessidade de considerar outras dimensões, como as configurações institucionais, os contextos estruturais e a cultura política, abandonando a ênfase demasiada em ações baseadas em valores e reflexividade de consumidores individuais no mercado.

Ao contrário de indivíduos e ONGs dos países do Norte Global, que são muito ativos em atacar as empresas e usar as quatro formas de consumo político para pressionar o mercado e, assim, produzir mudanças sociais, os movimentos sociais latino-americanos se concentram em lutar contra o capitalismo e o sistema neoliberal, pressionando para a construção de um Estado mais forte e democrático, que regule o mercado e invista em políticas públicas. Um fator importante para explicar essa diferença é a forte tradição coletivista dos movimentos sociais latinoamericanos, que priorizam o fortalecimento do poder regulatório do Estado em democracias frágeis, secundarizando a ação de indivíduos no mercado (BARBOSA et al., 2014).

O campo de batalha principal dos movimentos sociais latino-americanos, portanto, como mostram Barbosa et al. (2014) e Portilho e Micheletti (2018), é a arena institucional e não tanto o mercado. 


\section{Considerações finais}

Propus neste artigo a caracterização do ativismo alimentar brasileiro em duas gerações, a primeira relacionada à politização da alimentação, com ênfase em temas éticos, e a segunda relacionada à politização da comida e do comer, com tendência à convergência de temas éticos e estéticos. Mostrei, porém, que não se trata de diferenças fundamentais, no sentido da substituição de uma geração por outra, mas de um processo de ampliação de temas, atores e estratégias políticas. Outros estudos são necessários para documentar melhor essa caracterização.

Com relação às estratégias políticas da segunda geração de ativismo alimentar, destaquei a organização de diversos modelos de cadeias alimentares curtas e a politização do consumo alimentar. Mostrei, entretanto, que a literatura recente sobre consumo político vem ampliando o foco inicial nas ações no mercado de um consumidor individual reflexivo para enfatizar análises que considerem arranjos institucionais e estruturais, tecnologias, cultura política e práticas sociais cotidianas.

Em seguida, apresentei dados de pesquisas recentes que indicam duas especificidades do ativismo alimentar na América Latina. Em primeiro lugar, o consumo político, da forma como apresentado inicialmente na literatura, ou seja, como ação política de consumidores individuais no mercado, não parece ser o principal repertório dos movimentos de ativismo alimentar da região, sendo conjugado, e por vezes secundarizado, em relação às ações na esfera institucional do Estado, visando seu fortalecimento como agente regulador e a construção de políticas públicas, como faziam os movimentos da primeira geração. Em segundo lugar, parece haver convergência entre questões éticas e estéticas no ativismo alimentar da região, mas com esforço em não secundarizar os aspectos éticos.

As ambiguidades e desconfortos em lidar com o consumo político, observados nas pesquisas citadas, em especial no que se refere à compreensão do consumidor como uma categoria política e do consumo como uma esfera politizada, levam os ativistas alimentares a manter a política na esfera da luta de classes, nas desigualdades sociais e na categoria trabalhador.

De fato, e como mencionado anteriormente, a literatura mais recente sobre consumo político e, em especial, sobre consumo político alimentar, tem apontado que a melhor forma de estudar este fenômeno não parece ser aquela que analisa ações de indivíduos no mercado, baseadas em valores e reflexividade. Diversos autores (HALKIER, 2019; HALKIER; HOLM, 2008; SHOVE, 2003; OOSTERVEER et al., 2019) chamam a atenção para o problema de se negligenciar a forma como as práticas cotidianas são rotinizadas e moldadas por conhecimentos tácitos, convenções de normalidade, materialidades e tecnologias, propondo a incorporação de contribuições da Teoria das Práticas Sociais nos estudos sobre consumo político alimentar.

Comer, afinal, é uma prática mundana emaranhada em diversas outras, como comprar alimentos, levá-los para casa, estocá-los, selecionar menus, preparar refeições e servir. Além disso, as rotinas alimentares estão ligadas a convenções de normalidade, como o amor, a sociabilidade e a parentalidade. Finalmente, a Teoria das Práticas Sociais lança luz sobre a importância de aspectos como o uso do tempo e a busca pela praticidade no comer cotidiano. Tudo isso faz com que eventuais 
engajamentos políticos se percam nas rotinas diárias. Por outro lado, quando a comida ganha visibilidade na vida diária, seu caráter de incorporação pode levar a um nível mais alto de preocupação sobre o que é consumido (HALKIER, 2019) e, portanto, a novos engajamentos políticos.

Entretanto, ainda são poucos os estudos que focam as práticas sociais para entender como o consumo político alimentar se operacionaliza. Isso acontece mesmo nos países do Norte Global, onde esta é uma forma de participação frequente, e onde é realizada a maioria das pesquisas sobre o tema. Após um levantamento e análise de pesquisas sobre consumo político alimentar nos principais periódicos acadêmicos da área, Halkier (2019) mostra que a maioria ainda enfoca o consumidor individual, embora reconheça a complexidade das relações entre atores e arranjos políticos ${ }^{13}$.

Analisar como o consumo político alimentar se operacionaliza nas práticas cotidianas é, portanto, um campo de pesquisa aberto e necessário. Faz-se necessário, ainda, realizar estudos que analisem o que acontece com o consumo político alimentar em momentos de predomínio de políticas de austeridade, de decrescimento econômico e de governos ditatoriais. Outro ponto importante é examinar as transformações no consumo alimentar e no uso político do mesmo, em momentos de crise sanitária, como a enfrentada globalmente desde o fim de 2019.

\section{REFERÊNCIAS}

ARIZTIA, T. et al. Beyond the "deficit discourse": Mapping ethical consumption discourses in Chile and Brazil. Environment and Planning A, v. 48, n. 5, p. 891-909, 2016. DOI 10.1177/0308518X16632757.

ARIZTIA, T. et al. Ethical consumption in Brazil and Chile: Institutional contexts and development trajectories. Journal of Cleaner Production, v. 63, n. 15, p. 84-92, 2013.

ARIZTIA, T.; AGLONI, N.; PELLANDINI-SIMÁNYI, L. Ethical living: relinking ethics and consumption through care in Chile and Brazil. British Journal of Sociology, v. 69, n. 2, p. 391-411, 2018. DOI 10.1111/1468-4446.12265.

AZEVEDO, E. de. Alimentação, sociedade e cultura: Temas contemporâneos. Sociologias, v. 19, n. 44, p. 276-307, 2017. DOI 10.1590/15174522-019004412.

AZEVEDO, E. de. O ativismo alimentar na perspectiva do locavorismo. Ambiente \& Sociedade, v. 18, n. 3, p. 81-98, 2015. DOI 10.1590/1809-4422asoc740v1832015.

BARBOSA, L. A ética e a estética da alimentação contemporânea. In: CRUZ, F. T. da;

\footnotetext{
${ }^{13}$ Na América Latina, menciono a Tese de Doutorado de Fredy López-Pérez (LÓPEZ-PÉREZ, 2019), defendida na Universidad Tecnológica de Pereira, Colômbia, e que tive a oportunidade de co-orientar, que buscou a Teoria das Práticas Sociais para analisar o consumo sustentável, neste caso com foco no uso de água e energia em domicílios urbanos. Ver também (LÓPEZ-PÉREZ; GUERRERO-ERAZO, 2017).
} 
MATTE, A. (org.). Produção, consumo e abastecimento de alimentos. Porto Alegre: Editora da UFRGS, 2016, p. 95-123.

BARBOSA, L. Tendências da alimentação contemporânea. In: PINTO, M. L.; PACHECO, J. K (org.). Juventude, consumo e educação. Porto Alegre: ESPM, 2009, p. $15-61$.

BARBOSA, L.; PORTILHO, F.; WILKINSON, J.; DUBEUX, V. Trust, participation and political consumerism among Brazilian youth. Journal of Cleaner Production, v. 63, 2014. DOI 10.1016/j.jclepro.2013.08.044.

BENINI, M. L. de A. Transição agroecológica na perspectiva do consumo: um olhar etnográfico em um grupo de CSA (Community Supported Agriculture). Dissertação de Mestrado, Unicamp, 2018.

BOSTRÖM, M.; MICHELETTI, M.; OOSTERVEER, P. Studying Political Consumerism. In: BOSTRÖM, M.; MICHELETTI, M.; OOSTERVEER, P. (org.). The Oxford Handbook of Political Consumerism. Oxford: Oxford University Press, 2019. p. xvi-24. DOI 10.1093/oxfordhb/9780190629038.013.44.

BRANDENBURG, A.; LAMINE, C.; DAROLT, M. Institucionalização do movimento ecológico na agricultura: Mercado e reorganização dos atores sociais. In: BRANDENBURG, A.; BILLAUD, J.; LAMINE, C. (org.). Redes de agroecologia: experiência no Brasil e França. Curitiba: Kairós Edições, 2015, p. 87-110. BRASIL. Guia Alimentar para a População Brasileira. Brasília: Ministério da Saúde, 2014.

CAMPBELL, C. A ética romântica e o espírito do consumismo moderno. Rio de Janeiro: Rocco, 2001.

CASSOL, A.; SCHNEIDER, S. Produção e consumo de alimentos: Novas redes e atores. Lua Nova, v. 1, n. 95, p. 143-180, 2015. DOI 10.1590/0102-6445143-177/95. CASTRO, J. de. Geografia da Fome. 5 a edição ed. Rio de Janeiro: Civilização Brasileira, 2005.

CAYRES, D. C. Ativismo institucional e interações Estado-movimentos sociais. Revista Brasileira de Informação Bibliográfica em Ciências Sociais - BIB, v. 2016, p. 81-104, 2017.

CHARÃO-MARQUES, F.; SCHMITT, C. J.; OLIVEIRA, D. Agências e associações nas redes de agroecologia: práticas e dinâmicas de interação na serra gaúcha e na zona da mata mineira. Século XXI - Revista de Ciências Sociais, v. 7, n. 1, p. 15, 2017. DOI $10.5902 / 2236672528128$.

COUNIHAN, C.; SINISCALCHI, V. Food Activism - Agency, democracy and economy. London/New York: Bloomsbury Academic, 2014. 
DAMATTA, R. O que faz o brasil, Brasil? Rio de Janeiro: Rocco, 1986.

DAROLT, M. Circuitos curtos de comercialização de alimentos ecológicos: Reconectando produtores e consumidores. In: NIEDERLE, P. A.; ALMEIDA, L. de; VEZZANI, F. M. (org.). Agroecologia: Práticas, mercados e políticas para uma nova agricultura. Curitiba: Kairós, 2013, p. 139-170.

DIANI, M. Modes of Coordination in Political Consumerism. In: BOSTRÖM, M.; MICHELETTI, M.; OOSTERVEER, P. (org.). The Oxford Handbook of Political Consumerism. Oxford: Oxford University Press, 2019, p. 89-109. DOI 10.1093/oxfordhb/9780190629038.013.5.

DUBUISSON-QUELLIER, S. From Moral Concerns to Market Values: How Political Consumerism Shapes Markets. In: BOSTRÖM, M.; MICHELETTI, M.; OOSTERVEER, P. (org.). The Oxford Handbook of Political Consumerism. Oxford: Oxford University Press, 2019, p. 812-832. DOI 10.1093/oxfordhb/9780190629038.013.36.

FAO; IFAD; WFP. Strengthening the enabling environment for food security and nutrition. Rome: FAO/IFAD/WFP, 2014.

FISCHLER, C. Gastro-nomía y gastro-anomía: sabiduría del cuerpo y crisis biocultural de la alimentación contemporánea. Gazeta de Antropología, v. 26, n. (1) March, p. 357-380, 2010.

FORNO, F. Protest, Social Movements, and Spaces for Politically Oriented Consumerist Actions - Nationally, Transnationally, and Locally. In: BOSTRÖM, M.; MICHELETTI, M.; OOSTERVEER, P. (org.). The Oxford Handbook of Political Consumerism. Oxford: Oxford University Press, 2019, p. 69-88. DOI 10.1093/oxfordhb/9780190629038.013.4. FREITAS, A. de B. Aliança entre Movimentos Ambientalistas e de Consumidores: 0 caso da "Campanha por um Brasil Livre de Transgênicos". Dissertação de Mestrado, UFRRJ, 2011.

GENDRON, C.; BISAILLON, V.; RANCE, A. I. O. The institutionalization of fair trade: More than just a degraded form of social action. Journal of Business Ethics, v. 86, n. SUPPL. 1, p. 63-79, 2009. DOI 10.1007/s10551-008-9758-4.

GOODMAN, D. The quality 'turn' and alternative food practices: reflections and agenda. Journal of Rural Studies, v. 19, n. 1, p. 1-7, 2003. DOI 10.1016/s07430167(02)00043-8.

GOODMAN, D.; DUPUIS, M. E. Knowing food and growing food: Beyond the production-consumption debate in the sociology of agriculture. Sociologia Ruralis, v. 42, n. 1, p. 5-22, 2002. DOI 10.1111/1467-9523.00199.

GOODMAN, D.; DUPUIS, M. E.; GOODMAN, M. Alternative food networks Knowledge, practice, and politics. London/New York: Routledge, 2012. 
GUILHERME, N. O. S.; PORTILHO, F. Ecochefs, tapiocas e a gastronomização da agricultura familiar. In: GARSON, M.; TORQUATO, S. (org.). Alimentação e ciências sociais: Perspectivas contemporâneas. Rio de Janeiro: Autografia, 2018, p. 93-119.

GUILHERME, N. O. S. Produtores, Ecochefs e Consumidores - A Gastronomização da Agricultura Familiar no Circuito Carioca de Feiras Orgânicas. Dissertação de Mestrado, UFRRJ, 2016.

GUIVANT, J. S.; SPPARGAREN, G.; RIAL, C. (Org.). Novas práticas alimentares no mercado global. Florianópolis: Editora da UFSC, 2010.

HALKIER, B. Political Food Consumerism between Mundane Routines and Organizational Alliance-Building. In: BOSTRÖM, M.; MICHELETTI, M.; OOSTERVEER, P. (org.). The Oxford Handbook of Political Consumerism. Oxford: Oxford University Press, 2019, p. 274-292. DOI 10.1093/oxfordhb/9780190629038.013.11.

HALKIER, B.; HOLM, L. Food consumption and political agency: On concerns and practices among Danish consumers. International Journal of Consumer Studies, v. 32, n. 6, p. 667-674, 2008. DOI 10.1111/j.1470-6431.2008.00695.x. .

IPEA. Caderno ODS 2 - Fome Zero e Agricultura Sustentável. Instituto de Pesquisa Econômica Aplicada - Ipea. Brasília: Ipea, 2019.

JAGER, J. N. W. de. Political Consumerism in the South African and British AntiApartheid Movements. In: BOSTRÖM, M.; MICHELETTI, M.; OOSTERVEER, P. (org.). The Oxford Handbook of Political Consumerism. Oxford: Oxford University Press, 2019, p. 46-66, 2019. DOI 10.1093/oxfordhb/9780190629038.013.46.

LEÃO, M.; MALUF, R.S. A construção social de um sistema público de segurança alimentar e nutricional: a experiência brasileira. Brasília: Abrandh, 2012.

LIEN, M. E.; NERLICH, B. The politics of food: An introduction. In: LIEN, M. E.; NERLICH, B. (org.). The politics of food. Oxford: Berg, 2004, p. 01-07.

LÓPEZ-PÉREZ, F. Transiciones a consumo sostenible de las prácticas sociales asociadas al uso de agua y energía en hogares. Tese de Doutordao, Universidad Tecnológica de Pereira, 2019.

LÓPEZ-PÉREZ, F.; GUERRERO-ERAZO, J. Consideraciones ambientales sobre las prácticas de consumo de agua y energía en hogares urbanos. Revista Espacios, v. 38, n. 59, 2017. DOI 10.25100/rc.v20i2.4609.

MENASCHE, R. Saberes e sabores da colônia: alimentação e cultura como abordagem para o estudo do rural. Porto Alegre: UFRGS, 2015.

MENEZES, S. de S. M.; CRUZ, F. T. da. Estreitando o diálogo entre alimentos, 
tradição, cultura e consumo. São Cristóvão: Editora da Universidade Federal de Sergipe, 2018.

MICHELETTI, M.; STOLLE, D. Consumer Strategies in Social Movements. In: DELLA PORTA, Donatella; DIANI, Mario (org.). The Oxford Handbook of Social

Movements. Oxford: Oxford University Press, 2014, p. 1-18. DOI 10.1093/oxfordhb/9780199678402.013.45.

MONTICELLI, L.; DELLA PORTA, D. The Successes of Political Consumerism as a Social Movement. In: BOSTRÖM, Magnus; MICHELETTI, Michele; OOSTERVEER, Peter (org.). The Oxford Handbook of Political Consumerism. Oxford: Oxford University Press, 2019, p. 772-792. DOI 10.1093/oxfordhb/9780190629038.013.33.

MOTTA, R. Entre Controvérsia e Hegemonia: os transgênicos na Argentina e no Brasil. Rio de Janeiro: Editora da Fiocruz, 2018.

NIEDERLE, P. A.; WESZ JUNIOR, V. As novas ordens alimentares. Porto Alegre: Editora da UFRGS, 2018.

OLIVEIRA, D. C. de. Comida, carisma e prazer: Um estudo sobre a constituição do Slow Food no Brasil. Tese de Doutordao, 2014.

OOSTERVEER, P. et al. Political Consumerism and the Social-Practice Perspective. In: BOSTRÖM, Magnus; MICHELETTI, Michele; OOSTERVEER, Peter (org.). The Oxford Handbook of Political Consumerism. Oxford: Oxford University Press, 2019, p. 134156, 2019. DOI 10.1093/oxfordhb/9780190629038.013.8.

PORTILHO, F. Novos atores no mercado: movimentos sociais econômicose consumidores politizados. Revista Política \& Sociedade (Dossiê Sociologia Econômica), v. 8, n. 15, p. 199-224, 2009.

PORTILHO, F. et al. Novos espaços de experimentações: produtores, consumidores e ecochefs em feiras orgânicas cariocas. In: MENEZES, S. de S. M.; CRUZ, F. T. da (org.). Estreitando o diálogo entre alimentos, tradição, cultura e consumo. São Cristóvão: Editora da Universidade Federal de Sergipe, 2018, p. 93-114.

PORTILHO, F.; BARBOSA, L. A adesão à "causa” rural e da agricultura familiar por consumidores e seus movimentos organizados. In: MARQUES, F. C.; CONTERATO, M.; SCHNEIDER, S. (org.). Construção de mercados e agricultura familiar: desafios para o desenvolvimento rural. Porto Alegre: Editora da UFRGS, 2018, p. 251-273.

PORTILHO, F.; CASTAÑEDA, M.; CASTRO, I. R. R de. A alimentação no contexto contemporâneo: Consumo, ação política e sustentabilidade. Ciencia e Saude Coletiva, v. 16, n. 1, p. 99-106, jan. 2011. DOI 10.1590/s1413-81232011000100014.

PORTILHO, F.; FERREIRA, I. L. Redes alimentares alternativas no Brasil. In: LEITE, S. P.; BRUNO, R. (org.). O rural brasileiro na perspectiva do século XXI. Rio de Janeiro: 
Garamond, 2019, p. 189-203.

PORTILHO, F.; MICHELETTI, M. Politicizing Consumption in Latin America. In: BOSTRÖM, M.; MICHELETTI, M.; OOSTERVEER, P. (org.). The Oxford Handbook of Political Consumerism. Oxford: Oxford University Press, 2018, p. 539-557. DOI 10.1093/oxfordhb/9780190629038.001.0001.

POULAIN, J. Sociologias da alimentação. Os comedores e o espaço social alimentar. Florianópolis: Ed. UFSC, 2006.

PREISS, P. V. As alianças alimentares colaborativas em uma perspectiva internacional: Afetos, conhecimento incorporado e ativismo político. Tese de Doutorado, UFRGS, 2017.

SANTOS JUNIOR, J. L. dos; CASTRO, B. S. de; PORTILHO, F. Movimentos sociais, riscos e novas tecnologias: Ensaio sobre as disparidades no processo de politização. Teoria e Sociedade, v. 21, n. 218-142, 2013.

SASSATELLI, R. Virtue, Responsibility and Consumer Choice - Framing Critical Consumerism. In: TRENTMANN, F.; BREWER, J. (org.). Consuming cultures, global perspectives - Historical trajectories, transnational exchanges. Oxford/Nwe York: Berg, 2006, p. 219-250.

SHOVE, E. Comfort, Cleanliness and Convenience - The Social Organization of Normality. Oxford/Nwe York: Berg, 2003.

STOLLE, D.; HOOGHE, M.; MICHELETTI, M. Politics in the supermarket: Political consumerism as a form of political participation. International Political Science Review, v. 26, n. 3, 2005. DOI 10.1177/0192512105053784.

TANAKA, J.; PORTILHO, F. (Re)conexões entre produção e consumo no sistema agroalimentar: o Movimento dos Trabalhadores Rurais Sem Terra - MST e a politização da alimentação. INTERNATIONAL CONFERENCE ON AGRICULTURE AND FOOD IN AN URBANIZING SOCIETY, 3, 2018, Porto Alegre. Anais... Porto Alegre: UFRGS, 2018.

TANAKA, Jennifer Harumi. “Comer é um ato político": O Movimento dos Pequenos Agricultores (MPA) e a politização do consumo. 2019. 139f. Dissertação (Programa de Pós-Graduação de Ciências Sociais em Desenvolvimento, Agricultura e Sociedade) - Universidade Federal Rural do Rio de Janeiro, Rio de Janeiro, 2019.

TANAKA, J.; PORTILHO, F. Ambiguidades da politização do consumo: O caso do Movimento dos Pequenos Agricultores (MPA) na cidade do Rio de Janeiro. Revista Raízes, v. 39, n. 2, p. 344-358, 2019. DOl https://doi.org/10.37370/raizes.2019.v39.114.

TRENTMANN, F. Beyond Consumerism: New Historical Perspectives on Consumption. Journal of Contemporary History, v. 39, n. 3, p. 373-401, 2004. 
TRENTMANN, F. Citizenship and consumption. Journal of Consumer Culture, v. 7, n. 2, p. 147-158, 2007. DOI 10.1177/1469540507077667.

TRENTMANN, F. The modern genealogy of the consumer: meanings, identities and political synapses. In: BREWER, J.; TRENTMANN, F. (org.). Consuming cultures: global perspectives, historical trajectories, transnational exchanges. New York: Berg, 2006, p 19-69.

VASCONCELOS, F. de A. G. de. Josué de castro e a geografia da fome. Cadernos de Saúde Pública, v. 24, n. 11, p. 2710-2717, 2008. DOI 10.1590/S1517-45222014000100011.

WILKINSON, J. Recognition and Redistribution in the Renegotiation of Rural Space: The Dynamics of Aesthetic and Ethical Critiques. In: GOODMAN, M.; GOODMAN, D; REDCLIFT, M. (org.). Consuming Space: Placing Consumption in Perspective. London: Ashgate, 2010.

WILKINSON, J.; NIEDERLE, P. A.; MASCARENHAS, G. C. C. O sabor da origem Produtos territorializados na nova dinâmica dos mercados alimentares. Porto Alegre: Escritos do Brasil, 2016.

ZANETI, T. B.; SCHNEIDER, S. A conversa chegou à cozinha: Um olhar sobre o uso de produtos agroalimentares singulares na gastronomia contemporânea. Revista Mundi Meio Ambiente e Agrárias, v. 1, n. 1, p. 1-27, 2016. DOI http://dx.doi.org/10.21575/2525479ormmaa2016vol1n1125.

Fátima Portilho. CPDA - Programa de Pós-Graduação de Ciências Sociais em Desenvolvimento, Agricultura e Sociedade UFRRJ - Universidade Federal Rural do Rio de Janeiro.faportilho@yahoo.com.br

Como citar: PORTILHO, Fátima. Ativismo alimentar e consumo político - Duas gerações de ativismo alimentar no Brasil. Redes (St. Cruz Sul, Online), Santa Cruz do Sul, v. 25, n. 2, p. 411-432, maio 2020. ISSN 1982-6745. Disponível em: https://doi.org/10.17058/redes.v25i2.15088 